\title{
A National Virtual Research Training Workshop for 3800 Medical Students: A Mixed-Methods Evaluation of A Novel Research Education Program
}

\section{Asma Altaf Hussain Merchant}

Medical College, Aga Khan University Hospital

Abdullah Saeed Khan

Medical College, Aga Khan University Hospital

\section{Saadia Abbas}

Medical College, Aga Khan University Hospital

Maha Inam

Medical College, Aga Khan University Hospital

Ali Aahil Noorali

Medical College, Aga Khan University Hospital

Hamna Shahbaz

Medical College, Aga Khan University Hospital

Muhammad Daniyal Musharraf

Medical College, Aga Khan University Hospital

Faiqa Aamir

Medical College, Aga Khan University Hospital

Hareem Rauf

Medical College, Aga Khan University Hospital

Farah Khalid

Medical College, Aga Khan University Hospital

Fyezah Jehan

Medical College, Aga Khan University Hospital

Babar Hasan

Medical College, Aga Khan University Hospital

Muhammed Tariq

Medical College, Aga Khan University Hospital

Adil Haider ( $\boldsymbol{\nabla}$ adil.haider@aku.edu )

Medical College, Aga Khan University Hospital 
Keywords: Education, Distance, Research, Ethics, Research, Research Design

Posted Date: April 14th, 2021

DOI: https://doi.org/10.21203/rs.3.rs-384338/v1

License: (c) (1) This work is licensed under a Creative Commons Attribution 4.0 International License. Read Full License 


\section{Abstract}

\section{Background}

Research training is necessary to fill the burgeoning global decline in physician-scientists, which is further pronounced in developing countries. This has generated much interest within institutions across the world to increase research exposure for students as part of medical school curricula. In order to produce a cadre of aspiring physician-scientists, the Student Research Forum (SRF) at Aga Khan University conducted a series of online research workshops leveraging innovative technological solutions during the COVID-19 pandemic. Our study aims to explore students' perceptions of engaging undergraduate medical students in online research training workshops and to evaluate the effectiveness of such interventions in improving the knowledge and skillset of participating students.

\section{Methods}

'A Beginners Guide to Research' was a nation-wide virtual research workshop series conducted for medical students across Pakistan in June 2020. A mixed-methods study design was employed to evaluate course efficacy in terms of course content, duration and strategy. Dissemination of quantitative feedback forms alongside simultaneous conduction of qualitative interviews were used to receive feedback for the workshop and obtain the perspectives of medical students on the effectiveness of educational interventions in improving research-related knowledge.

\section{Results}

A total of 3,862 medical students enrolled in the national workshop series. The feedback form was completed by 2,754 participants, hailing from 113 universities across 37 cities in Pakistan. 2,311 (84.0\%) participants stated that the course helped them improve their overall research knowledge and 2,333 $(84.7 \%)$ felt confident that the skills learnt would help them in future research projects. 40 participants from 25 institutions across Pakistan participated in the qualitative interviews. 24 (60.0\%) participants had no prior knowledge of research, 23 (57.5\%) found virtual screen-sharing to be the most useful learning strategy and $22(55.0 \%)$ students expressed interest in initiating/expanding their institutional research platforms.

\section{Conclusion}

This nation-wide series presented a way in which alternative pedagogies can be used for the dissemination of research knowledge and skills to medical students with a strong inclination towards research. Efforts must be made by institutions to provide opportunities to medical students for engaging in meaningful scientific research during the COVID-19 pandemic and beyond.

\section{Background}


The declining numbers of physician-scientists globally is a challenge that requires urgent attention. This deficit is coupled with an increasing lack of enthusiasm demonstrated by budding physicians to partake in meaningful scientific research. The dearth of trained physician-scientists has necessitated the need to implement coordinated efforts to reverse this trend [1].

Various reasons have been cited by medical students to explain a lack of interest in research such as preference for direct patient care, absence of mentorship in research-related activities, decreased desire to prolong academic careers, accrual of student debt during medical school training, striking an appropriate work/life balance and lack of funding opportunities for research [2-4]. In response to this physicianscientist shortage, a multitude of solutions have been proposed by countries around the world to give medical students a holistic exposure to scientific research and to develop the prerequisite skills needed for a successful career in academic research [1]. Some notable programs include development of nationwide research programs in Norway and introduction of online research courses by the United States $[5,6]$. Other strategies include research methodology workshops (Saudi Arabia), innovative research fairs (Germany) and medical student research groups (Egypt) to increase medical students' interest in research [7-9].

Formal research training is not being given the due importance as it still remains non-uniformly incorporated into medical school curricula. A vast majority of students felt that medical research was often viewed as an extra-curricular activity in medical school, with a huge focus directed on basic and clinical sciences subjects. ${ }^{6}$ Recent initiatives in establishing better research opportunities for students within the medical curricula in developed countries have been a responding action to this demand $[6,7]$.

In Pakistan, several studies have shown the undeniable research interest that prevails within the medical student community $[10,11]$, however, there is a continuous lack of research initiatives within the country, highlighting a huge gap between the demand and production of trained physician-scientists. In response to this situation, the Student Research Forum at the Aga Khan University conducted the first national research workshop to increase the knowledge and research skills of medical students across Pakistan. Due to limitations imposed by COVID-19, a novel virtual platform and latest technological solutions were used to deploy this nation-wide initiative. This use of technological modalities to ensure stability within medical education has opened a plethora of alternatives that can simultaneously be used to reach a larger audience of medical students and provide them with the research skillset required to become a competent academic clinician.

\section{Methods}

\section{Overall Study Design:}

The Student Research Forum (SRF) at Aga Khan University in Karachi, Pakistan employed a quasiexperimental design to conduct a workshop series for medical students across the country. The course content for this series was developed a priori with expert input and in concordance with the participants' 
level of comprehension and research knowledge. A mixed-methods approach was used to gauge the impact of the workshop; with online feedback survey forms for quantitative and focused group discussions (FGDs) for in-depth qualitative evaluation. All participants included within the study provided informed consent by completing a digital consent form. All methods were carried out in accordance with relevant guidelines and regulations, ie, the SRQR guidelines for qualitative research.

\section{Study Setting and Duration:}

The virtual research workshop series, titled as "A Beginner's Guide to Research", was advertised through various social media platforms, namely Facebook, Instagram and Twitter, enrolling medical students from across the country. The workshop included an orientation and four interactive live sessions which

took place using an online platform on alternate days within the span of one week from June $22^{\text {nd }}, 2020$ to June $27^{\text {th }} 2020$, each with a duration of approximately one hour. Figure 1 shows a comprehensive outline of the entire workshop series content along with key elements of the study methodology.

All the workshops were conducted on Zoom application Version: 5.0 .4 (25694.0524) and were broadcast as a live-streaming webinar through the Video IBM Channel to increase national accessibility of the sessions. At the end of each workshop, a Frequently Asked Questions (FAQ) document was circulated amongst the participants, including the key points pertaining to the specific topic, for further clarity and review.

To assess the impact and gain participants' perception of the workshop series, a feedback form was disseminated to all participants and qualitative interviews were conducted at the summit of the series, which largely constituted a FGD format. Each FGD consisted of 7-9 students and was conducted virtually on Zoom Application Version: 5.0.4 (25694.0524).

\section{Study participants, sampling and enrollment:}

Inclusion criteria for the enrollment of participants within the series required them to be currently enrolled in medical school. Participants who originally registered for the workshop but did not follow through till the end were excluded from the overall analysis. The quantitative survey form was disseminated to all participants who enrolled in the series. In parallel, convenience sampling was used for recruiting participants for the FGD. Qualitative data analysis occurred in conjunction with the FGDs, allowing the research team to continue recruiting participants until no new themes emerged. Thematic saturation was achieved after 5 FGDs.

Digital informed consent was procured from all participants prior to the start of the workshop series. A De-Identification code (D-ID) was assigned to each participant to maintain confidentiality and ensure privacy of data. 


\section{Study instrument 1 - Feedback Survey:}

The quantitative survey form solicited information on the objectives, content, delivery and duration of the course along with overall strengths and limitations of the series, using a standard 5-point Likert scale, asking respondents to indicate their level of agreement with prespecified sub-themes. Additionally, participants were asked to overall rate the workshop series using a rubric, identify its strongest feature and the areas requiring further improvement (See Additional File 1).

\section{Study instrument 2 - Focused Group Discussions:}

For the FGDs, a semi-structured qualitative interview guide (See Additional File 2) was developed through expert input and adaptation of previous instruments [12]. This guide was divided into three components and sub-components to establish standardization of the discussion. The developed questionnaire covered the following 3 major themes:

1. Participant Expectations: This theme allowed the participants to discuss their inspiration and motivation for registering in the workshop and whether their expectations were appropriately met.

2. Course Content: The satisfaction of participants with regards to the course content, duration and classroom format was discussed within this section, in addition to the strengths and limitations.

3. Impact Assessment: This theme allowed the participants to discuss any improvements that they felt regarding their research knowledge after the series and evaluated their confidence in independently conducting research in their respective institutions.

In each component, the leading question was left open-ended, followed by specific close-ended questions. Interviewers were also trained a priori and a pilot run was done to ensure identification and rectification of any obstacles. Each FGD was led by 3 members of the research team and a clinical research fellow, with 1 moderator and 2 other members for audio recording. Data collected through audio recordings was deidentified and transcribed verbatim prior to analysis.

\section{Statistical Analysis:}

Data from the feedback form was analyzed using StataCorp. 2019 (Stata Statistical Software: Release 16. College Station, TX: StataCorp LLC). Descriptive statistics of survey items were calculated. Frequencies and percentages were calculated for each component of the Likert scale evaluating subthemes and global rating of the workshop series, strengths and limitations.

Data from the FGDs was analyzed using NVivo software (version 12.6.0.959), according to the Braun and Clarke six-step process for thematic analysis [13]. An iterative coding process was used, where 4 members of the research team individually identified themes, sub-themes and codes using the transcribed verbatim. A consolidated codebook of 51 unique codes was generated. 2 members 
independently used NVivo to pair each transcribed statement with its equivalent code. The results were compared and a consensus was reached for each code, producing the results of the qualitative discussion as frequencies.

\section{Results}

\section{Quantitative Survey Results}

The feedback form was completed by 2,754 participants (response rate $=71.3 \%$ ). The participants had a mean (SD) age of $21.2 \pm 2.1$, with $27.5 \%$ males and $71.9 \%$ females. Additional demographic data for the participants can be found in Table 1.

Table 1

Demographic and enrollment characteristics of study participants

\begin{tabular}{|c|c|c|}
\hline Variable & Feedback Form Participants & FGD Participants \\
\hline No. of Respondents & 2754 & 40 \\
\hline No. of Cities & 37 & 9 \\
\hline No. of Universities & 113 & 25 \\
\hline Age, in years; (Mean $\pm S D)$ & $21.1 \pm 2.1$ & $20.9 \pm 2.0$ \\
\hline \multicolumn{3}{|l|}{ Gender } \\
\hline Male; n (\%) & $761(27.6 \%)$ & $13(32.5 \%)$ \\
\hline Female; n (\%) & 1979 (71.9\%) & $27(67.5 \%)$ \\
\hline Prefer not to answer; $\mathrm{n}(\%)$ & $14(0.5 \%)$ & $0(0.0 \%)$ \\
\hline \multicolumn{3}{|l|}{ Year of Study } \\
\hline Pre-Clinical Years; n (\%) & $1321(48.0 \%)$ & $18(45.0 \%)$ \\
\hline Clinical Years; n (\%) & $1433(52.0 \%)$ & $22(55.0 \%)$ \\
\hline \multicolumn{3}{|l|}{ Type of institution } \\
\hline Public; n (\%) & $1201(43.6 \%)$ & $22(55.0 \%)$ \\
\hline Private; n (\%) & $1553(56.4 \%)$ & $18(45.0 \%)$ \\
\hline
\end{tabular}

Table 1 highlights the demographic features of participants who completed the feedback forms and participated in Focused Group Discussions (FGDs).

Figure 2 comprehensively shows the level of agreement and/or disagreement that participants felt when evaluating specific qualitative feedback sub-themes. 2,311 (84.0\%) participants stated that the course 
helped them in improving their overall research knowledge and 2,333 (84.7\%) reported feeling confident that the skillset learnt through the series would help them in future research projects. The findings also revealed a high interest in 2,498 (90.8\%) participants for a future advanced research series.

Participants were also asked to nominate the area of the workshop that they felt was the strongest feature and the area that needed the most improvement. The two key areas that were identified by the highest number of participants as the main strength were course content $(n=853,31.0 \%)$ and delivery method and approach $(n=693,25.2 \%)$. Likewise, the two key areas that were identified to be the major limitation were course duration $(n=636,23.1 \%)$ and course video and sound quality $(n=478,17.4 \%)$. Majority of the students $(n=978,35.5 \%)$ rated the overall series as 'Excellent', followed by 'Very Good' $(n=879,31.9 \%)$ on the grading rubric.

\section{Thematic analysis of Focused Group Discussions (FGDs):}

A total of 40 participants took part in the FGDs, consisting of $13(32.5 \%)$ males and $27(67.5 \%)$ females, with a mean age of $20.9 \pm 2.0$ (Table 1). Thematic analysis (Table 2) exhibited the following noteworthy findings, extrapolated from the opinions shared by the FGD participants (Table 3).

Table 2

Thematic analysis of the ISGMs - themes, subthemes, codes and frequencies 


\begin{tabular}{|c|c|c|c|}
\hline Themes & Subthemes & Codes & $\begin{array}{l}\text { Frequency; } \\
\text { n (\%) }\end{array}$ \\
\hline \multirow{13}{*}{$\begin{array}{l}\text { 1. Motivating Factors } \\
\text { for Participation }\end{array}$} & \multirow[t]{3}{*}{ 1.1 Baseline Knowledge } & A. Had no prior knowledge & $24(60.0 \%)$ \\
\hline & & B. Had existing knowledge & $12(30.0 \%)$ \\
\hline & & C. No Response & $4(10.0 \%)$ \\
\hline & \multirow[t]{10}{*}{1.2 Inspirations } & $\begin{array}{l}\text { A. First of its kind workshop } \\
\text { in Pakistan }\end{array}$ & $4(10.0 \%)$ \\
\hline & & B. Learn about research & \multirow{2}{*}{$21(52.5 \%)$} \\
\hline & & C. Career advancement & \\
\hline & & D. E-Certificate & $21(52.5 \%)$ \\
\hline & & $\begin{array}{l}\text { E. Learn from leading experts } \\
\text { from } A K U H\end{array}$ & $11(27.5 \%)$ \\
\hline & & $\begin{array}{l}\text { F. Productive and efficient } \\
\text { use of time }\end{array}$ & \multirow{3}{*}{$\begin{array}{l}3(7.5 \%) \\
4(10.0 \%) \\
1(2.5 \%)\end{array}$} \\
\hline & & $G$ Eace of acrecc of a froe & \\
\hline & & online workshop & \\
\hline & & \multicolumn{2}{|l|}{ H. Recommendation } \\
\hline & & \multicolumn{2}{|l|}{ I. No Response } \\
\hline \multirow[t]{11}{*}{ 2. Workshop Strategy } & \multirow[t]{6}{*}{ 2.1 Teaching Pedagogy } & A. Presentations & $9(22.5 \%)$ \\
\hline & & $\begin{array}{l}\text { B. Live demonstration } \\
\text { (screen share) }\end{array}$ & $23(57.5 \%)$ \\
\hline & & C. Small classroom format & \multirow{4}{*}{$\begin{array}{l}9(22.5 \%) \\
2(5.0 \%) \\
8(20.0 \%)\end{array}$} \\
\hline & & D. Use of examples & \\
\hline & & E. Use of audio-visual media & \\
\hline & & F. No Response & \\
\hline & \multirow[t]{5}{*}{ 2.2 Logistics } & A. Internet connectivity & $10(25.0 \%)$ \\
\hline & & B. Video playback & $3(7.5 \%)$ \\
\hline & & $\begin{array}{l}\text { C. Clash with preexisting } \\
\text { commitments }\end{array}$ & \multirow{2}{*}{$\begin{array}{l}2(5.0 \%) \\
24(60.0 \%)\end{array}$} \\
\hline & & \multirow{2}{*}{ D. No challenges faced } & \\
\hline & & & $3(7.5 \%)$ \\
\hline \multirow[t]{2}{*}{$\begin{array}{l}\text { 3. Workshop Feedback } \\
\text { and Evaluation }\end{array}$} & \multirow[t]{2}{*}{ 3.1 Strengths } & $\begin{array}{l}\text { A. All session objectives } \\
\text { covered }\end{array}$ & $27(67.5 \%)$ \\
\hline & & B. Time duration per session & $5(12.5 \%)$ \\
\hline
\end{tabular}



C. Appropriate for beginners
$16(40.0 \%)$
D. Utility of pre and post tests
$14(35.0 \%)$
E. Ease of supplemental
7 (17.5\%)
documentation
F. Q\&A Session
G. No weakness
$2(5.0 \%)$
$5(12.5 \%)$
H. No Response

3.2 Limitations
A. Did not cover all objectives
$4(10.0 \%)$
B. Time duration per session
$22(55.5 \%)$
C. Too complex
$9(22.5 \%)$
D. Too basic
$13(32.5 \%)$
E. Insufficient time for Q\&A
$8(20.0 \%)$
F. No Response
$2(5.0 \%)$

3.3 Recommendations
for Improvement

A. Lecture recordings

$13(32.5 \%)$

B. Fewer participants

$10(25.0 \%)$

C. Greater interaction $20(50.0 \%)$

D. Homework and follow up assignments

E. Answer key and scores for pre and post tests $5(12.5 \%)$

F. Utilization of real time "chat-box" platform

G. Increased number of sessions

H. No Response

4. Impact Assessment

4.1 Ability to Implement

A. Ability to Undertake

$23(57.5 \%)$ Independent Projects

B. Expansion in own

$22(55.0 \%)$ Institutions

C. No Response

4.2 Interest in Advanced Workshops
A. Need to conduct an advanced series

B. Interest in attending an advanced series

C. No Response
$24(60.0 \%)$ 29 (72.5\%) 11 (27.5\%) 
Table 3

Representative Quotations from Qualitative Focused Group Discussions 


\begin{tabular}{|c|c|c|}
\hline Themes & Subthemes & Participant Quotations \\
\hline \multirow{6}{*}{$\begin{array}{l}\text { Motivating } \\
\text { Factors for } \\
\text { Participation }\end{array}$} & \multirow[t]{3}{*}{$\begin{array}{l}\text { Baseline } \\
\text { Knowledge }\end{array}$} & $\begin{array}{l}\text { Fifth Year, } 24 \text { y Male: "I learnt many things from this course. A } \\
\text { few topics were completely new for me..." }\end{array}$ \\
\hline & & $\begin{array}{l}\text { Fourth Year, } 20 \text { y Male: "I brushed up on a lot of things I knew } \\
\text { before, and I learned many new things too..." }\end{array}$ \\
\hline & & $\begin{array}{l}\text { Third Year, } 22 \text { y Female: "My knowledge improved a lot since I } \\
\text { didn't even know the ABC of research but now, I know how to } \\
\text { do referencing, write an abstract etc." }\end{array}$ \\
\hline & \multirow[t]{3}{*}{ Inspirations } & $\begin{array}{l}\text { Third Year, } 21 \text { y Female: "Develop basic skills as a beginner... } \\
\text { convenience of online sessions. Helps with residency } \\
\text { acceptance by giving you an edge over those who might have } \\
\text { similar STEP scores..." }\end{array}$ \\
\hline & & $\begin{array}{l}\text { Third Year, } 22 \text { y Male: "To improve my CV, get a certificate and } \\
\text { to improve my knowledge." }\end{array}$ \\
\hline & & $\begin{array}{l}\text { First Year, } 18 \text { y Male: "Curiosity for attending an online } \\
\text { workshop and learn more about research; E-certificate was a } \\
\text { minor inspiration." }\end{array}$ \\
\hline \multirow[t]{2}{*}{$\begin{array}{l}\text { Teaching } \\
\text { Format }\end{array}$} & \multirow[t]{2}{*}{$\begin{array}{l}\text { Teaching } \\
\text { Pedagogy }\end{array}$} & $\begin{array}{l}\text { Fifth Year, } 25 \text { y Female: "Giving us examples of research, } \\
\text { screensharing and showing us how to use the softwares really } \\
\text { allowed us to learn." }\end{array}$ \\
\hline & & $\begin{array}{l}\text { First Year, } 18 \text { y Male: " ...Examples and demonstration was } \\
\text { used to make the audience understand content." }\end{array}$ \\
\hline \multirow{8}{*}{$\begin{array}{l}\text { Workshop } \\
\text { Feedback } \\
\text { and } \\
\text { Evaluation }\end{array}$} & \multirow[t]{3}{*}{ Strengths } & $\begin{array}{l}\text { Fifth Year, } 23 \text { y Female: "The basic things were covered by all } \\
\text { the speakers and everything was explained..." }\end{array}$ \\
\hline & & $\begin{array}{l}\text { Second Year, } 21 \text { y Female: "I gained adequate knowledge } \\
\text { considering I'm a beginner and the management was really } \\
\text { good..." }\end{array}$ \\
\hline & & $\begin{array}{l}\text { First Year, } 18 \text { y Female: "Teachers taught right from the basics } \\
\text { so even a beginner could understand what was being taught." }\end{array}$ \\
\hline & \multirow[t]{2}{*}{ Limitations } & $\begin{array}{l}\text { Fifth Year, } 22 \text { y Female: "Final year to first year, all students } \\
\text { were dealt with the same way even though everyone has } \\
\text { different levels of introduction to research." }\end{array}$ \\
\hline & & $\begin{array}{l}\text { Second Year, } 19 \text { y Female: "If the sessions were over a longer } \\
\text { period of time with less duration, might have been more } \\
\text { beneficial because as a beginner it was difficult to take in } \\
\text { everything." }\end{array}$ \\
\hline & \multirow[t]{3}{*}{$\begin{array}{l}\text { Recommendations } \\
\text { for Improvement }\end{array}$} & $\begin{array}{l}\text { Fifth Year, } 23 \text { y Female: "Recorded lectures would be better for } \\
\text { next time..." }\end{array}$ \\
\hline & & $\begin{array}{l}\text { Second Year, } 21 \text { y Male: "Small group sessions could have } \\
\text { been conducted to increase interactions..." }\end{array}$ \\
\hline & & $\begin{array}{l}\text { First Year, } 18 \text { y Female: "Smaller groups. Better interaction. } \\
\text { Content should be according to comprehension level." }\end{array}$ \\
\hline
\end{tabular}




\begin{tabular}{|lll|}
\hline Themes & Subthemes & Participant Quotations \\
\hline $\begin{array}{l}\text { Impact } \\
\text { Assessment }\end{array}$ & $\begin{array}{l}\text { Ability to } \\
\text { Implement }\end{array}$ & $\begin{array}{l}\text { Fifth Year, } 23 \text { y Female: "I would love to do research myself and } \\
\text { will be able to conduct a similar workshop at my institution." } \\
\text { First Year, } 18 \text { y Female: "I believe I can do research } \\
\text { independently to some extent and will be able to teach and } \\
\text { conduct similar workshops, but with the help of colleagues." }\end{array}$ \\
& $\begin{array}{l}\text { Fifth Year, } 25 \text { y Female: "Will be interested in an advanced } \\
\text { workshop series. Should include how to assess journals for } \\
\text { Advanced } \\
\text { Workshops }\end{array}$ & $\begin{array}{l}\text { Second Year, 19 y Male: "I would be interested in attending a } \\
\text { future series, especially if it incorporates SPSS analysis." }\end{array}$ \\
& $\begin{array}{l}\text { First Year, 18 y Male: "Yes, will definitely think on participating } \\
\text { in it. Should include more advanced information on these } \\
\text { sessions and include steps on how to start off with research } \\
\text { since we know what to do but not sure about the platforms } \\
\text { where we can proceed with our research." }\end{array}$ \\
\hline
\end{tabular}

\section{Theme 1: Motivating Factors for Participation}

24 (60.0\%) participants reported no baseline knowledge regarding research, which motivated them to register for the series and particularly learn basic research skills $(n=36,90.0 \%)$. For example, a secondyear medical student commented, "We didn't have any orientation related to the concept of research; neither in first-year, nor in the second-year - so we wanted to learn about research." Similarly, another firstyear medical student was quoted as saying "... Wanted to start from scratch so really needed a basic course and a platform where people could tell me how research is done..."

Other factors that inspired registrations included the provision of certificates on the completion of the course $(n=21,52.5 \%)$, the possibility of developing an academically sound career $(n=21,52.5 \%)$ and the opportunity to learn from research experts affiliated with a leading research institute in the country $(n=13$, $32.5 \%)$.

\section{Theme 2: Teaching Format}

A hybrid teaching style, combining a presentation format and real-time practicing of problems, demonstrated through screen-sharing on Zoom was considered one of the best teaching methodologies employed by the workshop by $23(57.5 \%)$ participants, followed by the use of presentation and examples within the sessions by 9 (22.5\%) attendees each. For example, a fifth-year medical student stated that, "Screensharing, showing videos, relating content with real life and giving examples really helped in understanding the topic..." 
When participants were asked about any logistical issues encountered during the workshop, most of the students $(60.0 \%)$ did not face any challenges. However, 10 (25.0\%) respondents experienced internet connectivity issues and $3(7.5 \%)$ students reported interrupted livestreaming.

\section{Theme 3: Workshop Feedback and Evaluation}

27 (67.5\%) participants stated that the major strength of the workshop was the fulfillment of all stated objectives, while $16(40.0 \%)$ students felt that the course content was appropriate for beginners. One second-year medical student appreciated the "synchronization of content with objectives," and another stated: "I am satisfied with the content and objectives and how they were covered. It was pretty good and comprehensive for beginners."

Similar to the limitations highlighted in the feedback form, the duration of the sessions was considered a major shortcoming by $22(55.5 \%)$ participants. Furthermore, a significant variability was seen in the comprehension of the course content by students, which led some to find the course too basic $(n=13$, $32.5 \%)$, while others found it to be too complicated ( $n=9,22.5 \%)$.

\section{Theme 4: Impact Assessment}

$23(57.5 \%)$ participants stated their confidence in leading a research project after the course, along with $22(55.0 \%)$ students who showed interest in expanding a research platform within their institutions through dissemination of the learnt knowledge, as stated by a first-year medical student, "... I can teach and deliver the skills to students in my institution, at least the ones I learnt".

The possibility of an advanced workshop series was exciting for many participants, with 29 (72.5\%) attendees showing an interest in attending a future workshop series.

\section{Discussion}

Effective research in medicine provides an impetus for novel and innovative developments that ultimately allow us to find solutions to challenging and complex medical problems. This highlights the core principle behind conducting educational interventions to increase the knowledge and awareness of medical students regarding scientific research. The COVID-19 pandemic has brought about a major paradigm shift in teaching all over the world, with increased adoption of online means of instruction using various softwares such as video conferencing tools and webinars. Comparison studies including systematic reviews have tried to evaluate the efficacy of online-teaching pedagogies with the traditional in-person teaching methods, concluding a similar impression of efficacy between the two $[14,15]$.

An online format using Zoom was a strategy adopted due to social distancing restrictions posed by the COVID-19 pandemic and has proved to be an effective tool which allows researchers to qualitatively 
assess participant responses across the themes of discussion, increasing accessibility through the online nature of the FGDs [16].

Similar to our study where $24(60.0 \%)$ participants had no prior research knowledge owing to decreased opportunities, a study performed by Ejaz et.al in 2008 assessing research interest within final-year medical students and young graduates in Karachi, Pakistan showed that majority of the participants $(n=225,59.0 \%)$ considered their research exposure inadequate, even though they were keenly interested in medical research [10]. Several factors have shown to contribute to a medical student's interest in research, namely a good role model coupled with a strong research knowledge [17], which were also evident inspirations for registrations in our study.

The popular opinion within participants of using live demonstrations through screen sharing was consistent with literature that shows how case studies and video demonstrations were the most effective instructional strategies in an online course [18]. In addition, ensuring the fulfillment of all objectives and provision of supplementary reading material after virtual sessions allow increased information retention within the students. A systematic review has highlighted how web-based learning interventions can lead to ample gains in knowledge among medical students [19].

However, virtual teaching is still hindered by its limitations of decreased interaction between the speakers and participants, coupled with the issue of standardizing the course content for a diverse cohort. The latter has also been experienced within in-person sessions where the presence of diversity within the participants led to variable comprehension of the content being taught between them [20]. A study reported teaching-related factors as the main concern of students for video lectures which include lecture content, speaker, and delivery style rather than the technology employed [21]. This highlights the importance of paying attention to these logistical details for any teaching session, as was employed in our study to ensure quality transference of knowledge.

The efficacy of the series is showcased through the enthusiasm of $23(57.5 \%)$ participants who stated their confidence in leading research projects and workshops in their institutions. Ultimately, this can prove to be fruitful in the efforts to increase the number of publications from institutions in Pakistan, which is currently falling behind the rest of the world by a substantial margin [22].

The interest shown by 29 (72.5\%) participants towards an advanced research series is in accordance with the findings of a study which concluded online learning to be more convenient for students, allowing them to balance their studies, family, and extra-curricular activities [23]. This ignited interest can play a pivotal role in propagating research knowledge and may marginally compensate for the lack of a robust research curriculum in Pakistani medical schools, leading to the increased numbers of Pakistani physician-scientists in the years to come.

To the best of our knowledge, this was the first ever national research workshop conducted in Pakistan, using a virtual platform and made accessible to all medical students across the nation. The series ensured as much accessibility as possible to all medical students, regardless of their age, gender, 
geographical district, or financial status. All participant registrations were taken into consideration to keep the cohort diverse and allow for wider dissemination of research knowledge. Ensuring a safe space within the FGDs allowed participants to share their feedback candidly, without any hesitation.

A major limitation highlighted during the series was the inadequate duration of the sessions, which affected the quality of content delivery to the participants. This also resulted in the inability to ask all the questions provided by the participants through the email during the Questions and Answer (Q\&A) Section at the end. However, providing an FAQ document at the end of the sessions, aided participants to easily navigate through the workshop series.

In addition, connectivity issues and power outages often led the students to miss some sessions, but the FAQ documents helped in covering the gaps faced by them.

\section{Conclusions}

This first-ever national virtual research workshop series for undergraduate medical students paves the way for future similar series to be conducted in a manner more accessible and acceptable to a diverse cohort of students interested in learning the basics of research. The initial overwhelming response, with continuously high attendance in all the workshop sessions indicates the presence of a high research interest within undergraduate students paired with a lack of research opportunities within their teaching institutions. Hence, there is a need to further spread the current research interest and passion using similar platforms, standardized for students all over the nation with the provision of knowledge and skills at the undergraduate level where it can be well-received and appreciated.

\section{Abbreviations}

FGDs: Focused Group Discussions

FAQ: Frequently Asked Questions

\section{Declarations}

\section{Ethics approval and consent to participate:}

All participants included within the study provided informed consent by completing a digital consent form. This study was given ethics approval by the Aga Khan University's Ethics Review Committee (ERC Reference Number: 2020-5131-11751). All methods were carried out in accordance with relevant guidelines and regulations, i.e, the SRQR guidelines for qualitative research.

\section{Consent for publication:}

Not Applicable 


\section{Availability of data and materials:}

The datasets used and/or analyzed during the current study are available from the corresponding author on reasonable request.

\section{Competing interests:}

The authors declare that they have no competing interests.

\section{Funding:}

No funding was required for this study. The authors have no financial conflicts of interest to disclose.

\section{Authors' contributions:}

AAHM, MDM, AAN and MI conceived the idea of the study and developed the quantitative feedback survey and qualitative interview guide for the series. AAHM, AS, SA, MDM, AAN, MI, FA and HR collected and organized the data. AAN, HS and FK analyzed the results of the quantitative feedback forms. AAHM, AS, SA and MI analyzed the results of the qualitative focused group discussions. AAHM, AS, SA, MDM, $A A N, H S, M I, F A, H R$ and FK contributed within the writing of the manuscript. FJ, BH, MT and $A H$ supervised the process of this study, provided important intellectual feedback and contributed to the final manuscript. All authors reviewed the final manuscript and approved the submitted version.

\section{Acknowledgements:}

We would like to acknowledge the administration and official leadership of Student Research Forum (SRF) at Aga Khan University for their support and technological aid during the execution of the series.

\section{References}

1. Stone C, Dogbey G, Klenzak S, Van Fossen K, Tan B, Brannan G. Contemporary global perspectives of medical students on research during undergraduate medical education: a systematic literature review. Medical Education Online. 2018; 23(1):1537430.

2. Mahmood Shah S, Sohail M, Ahmad K, Imtiaz F, Iftikhar S. Grooming future physician-scientists: evaluating the impact of research motivations, practices, and perceived barriers towards the uptake of an academic career among medical students. Cureus. 2017;9(12):e1991.

3. Furuya $\mathrm{H}$, Brenner $\mathrm{D}$, Rosser $\mathrm{C}$. On the brink of extinction: the future of translational physicianscientists in the United States. J Transl Med. 2017;15(1):88. 
4. Yang V. The future of physician-scientists-demise or opportunity?. Gastroenterology. 2006;131(3):697-698.

5. Hunskaar S, Breivik J, Siebke M, Tømmerås K, Figenschau K, Hansen J. Evaluation of the medical student research programme in Norwegian medical schools. A survey of students and supervisors. BMC Medical Education. 2009;9(1):43.

6. Cruser D, Brown S, Ingram J, Podawiltz A, Dubin B, Colston J et al. Learning outcomes from a biomedical research course for second year osteopathic medical students. Osteopath Med Prim Care. 2010;4(1):4.

7. Abdulghani H, Shaik S, Khamis N, Al-Drees A, Irshad M, Khalil M et al. Research methodology workshops evaluation using the Kirkpatrick's model: translating theory into practice. Med Teach. 2014;36 Suppl 1:S24-29.

8. Steffen J, Grabbert M, Pander T, Gradel M, Kohler L, Fischer M et al. Finding the right doctoral thesis an innovative research fair for medical students. GMS Z Med Ausbild. 2015;32(3): Doc29.

9. Negida AS. Egypt's Premier Medical Student Research Group: A New Model for Medical Student Research in Developing Countries. Cureus. 2018;10(11):e3561.

10. Ejaz K, Shamim MS, Shamim MS, Hussain SA. Involvement of medical students and fresh medical graduates of Karachi, Pakistan in research. JPMA J Pak Med Assoc. 2011;61(2):115-20.

11. Baig S, Hasan S, Ahmed S, Ejaz K, Aziz S, Dohadhwala N. Reasons behind the increase in research activities among medical Students of Karachi, Pakistan, a low-income Country. Educ Health. 2013;26(2):117.

12. Krueger R. Developing Questions for Focus Groups [Internet]. Thousand Oaks, California: SAGE Publications, Inc.; 1998.

13. Braun V, Clarke V, Terry G. Thematic analysis. Rohleder P, Lyons A, editors. 2014.

14. Kyaw B, Posadzki P, Paddock S, Car J, Campbell J, Tudor Car L. Effectiveness of Digital Education on Communication Skills Among Medical Students: Systematic Review and Meta-Analysis by the Digital Health Education Collaboration. J Med Internet Res. 2019;21(8):e12967.

15. Rapanta C, Botturi L, Goodyear P, Guàrdia L, Koole M. Online University Teaching During and After the Covid-19 Crisis: Refocusing Teacher Presence and Learning Activity. Postdigital Sci Educ. 2020;2(3):923-945.

16. Bender $D$, Ewbank $D$. The focus group as a tool for health research: issues in design and analysis. Health Transit Rev. 1994;4(1):63-80.

17. Ha T, Ng S, Chen C, Yong S, Koh G, Tan S et al. Inclination towards research and the pursuit of a research career among medical students: an international cohort study. BMC Med Educ. 2018;18(1):86.

18. Yang D. Instructional strategies and course design for teaching statistics online: perspectives from online students. Int J STEM Educ. 2017 Dec 29;4(1):34. 
19. Chumley-Jones H, Dobbie A, Alford C. Web-based learning: sound educational method or hype? A review of the evaluation literature. Acad Med J Assoc Am Med Coll. 2002;77 Suppl 10:S86-93.

20. Nazha B, Salloum R, Fahed A, Nabulsi M. Students' Perceptions of Peer-Organized Extra-Curricular Research Course during Medical School: A Qualitative Study. PLOS ONE. 2015;10(3):e0119375.

21. Wang R, Mattick K, Dunne E. Medical students' perceptions of video-linked lectures and videostreaming. ALT-J. 2010;18(1):19-27.

22. Mushtaq A, Abid M, Qureshi M. Assessment of research output at higher level of educaton in Pakistan. JPMA J Pak Med Assoc. 2012 Jun;62(6):628-32.

23. Gaytan J, McEwen B. Effective Online Instructional and Assessment Strategies. Am J Distance Educ. 2007;21(3):117-32.

\section{Figures}

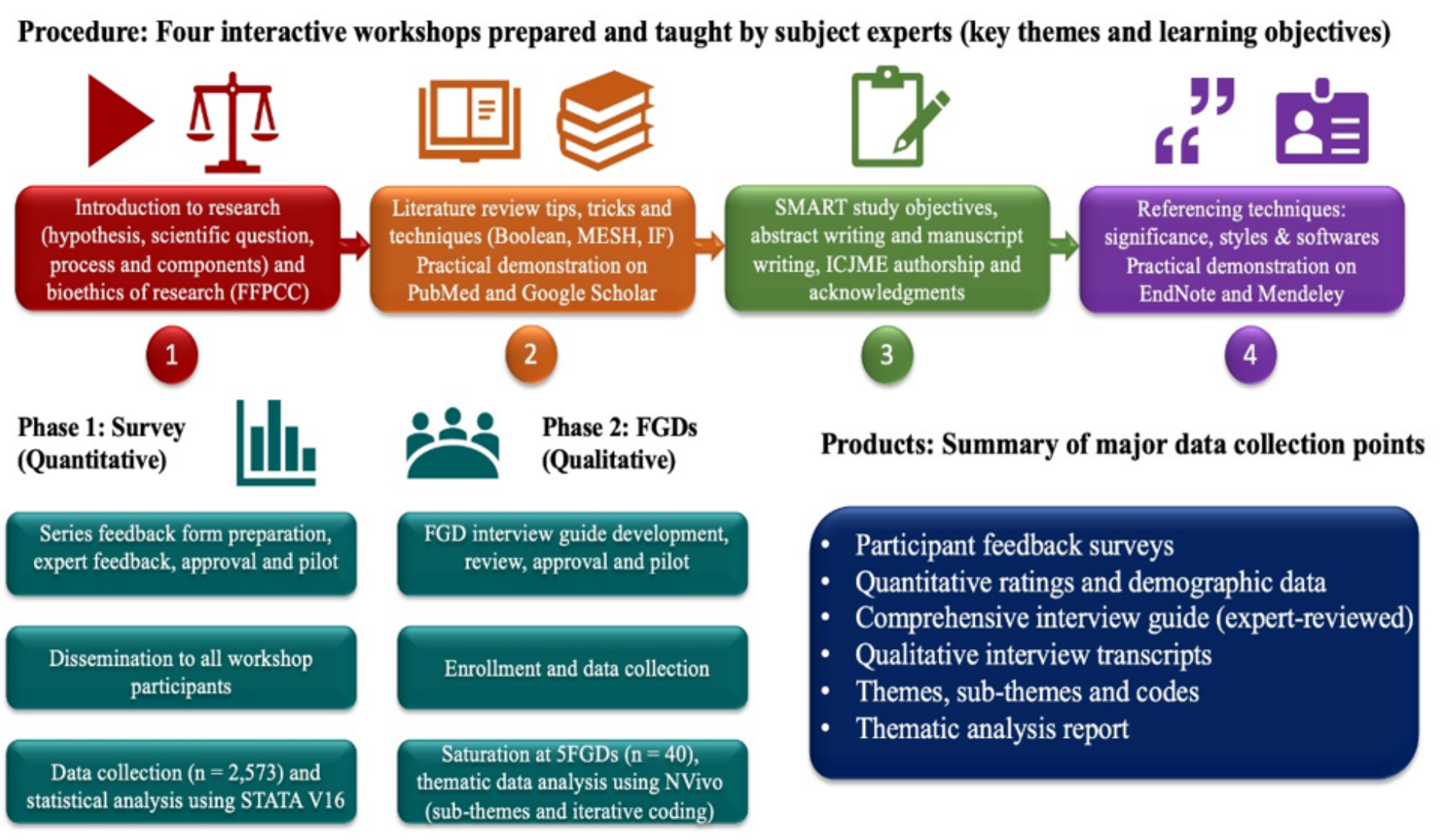

\section{Figure 1}

Title: A comprehensive overview of the workshop themes and study design (procedure, phases and products) Abbreviations within Figure 1: FFPCC = fabrication, falsification, plagiarism, communication, confidentiality; Boolean = boolean operators used in literature search; $\mathrm{MESH}=$ medical subject headings; IF = impact factor; SMART = specific, measurable, attainable, relevant, and time-bound; ICJME = International Committee of Medical Journal Editors; FGDs = focused group discussions 


\section{Feedback for the overall series using LIKERT's scale}

Confident that skills gained will help me partake in research

Course content was as per pariticipants' level of understanding

Course helped improvement overall knowledge in research basics

Course made it possible for participants to ask questions

Delivery of course objectives met the expectations before joining

Delivery style was easily understandable

Duration of each workshop was enough to cover all objectives

Duration of entire series was enough to cover all objectives Interested in participating in a future ADVANCED research series Made the correct decision to sign up for this BASIC research series Questions were adequetely answered by speakers Speakers had expertise over their subject matter

Speakers were efficient and clear in their content delivery

Speed of the course was suitable to understand the content Technical logistics were planned out properly for the entire course Would recommend a similar workshop to friends and colleagues

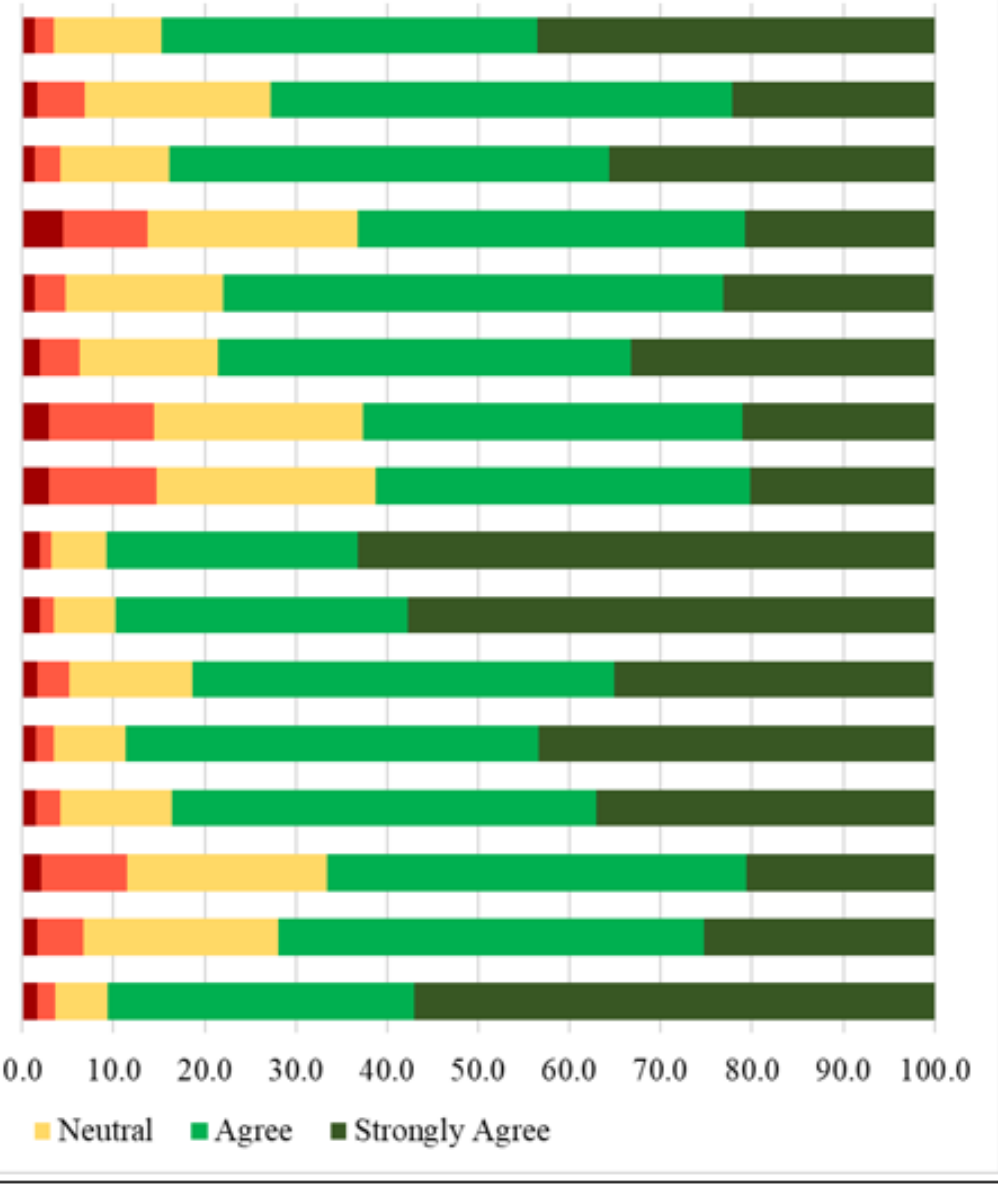

\section{Figure 2}

Title: Feedback for the overall series using LIKERT's scale Legend: Result of the feedback received from the participants of the workshop series regarding its impact, course content and duration.

\section{Supplementary Files}

This is a list of supplementary files associated with this preprint. Click to download.

- AdditionalFile1.docx

- AdditionalFile2.docx 